\title{
Effect of Calcium Nitrate and Sodium Nitrite on the Rebar Corrosion of Medium Carbon Steel in Seawater and Cassava Fluid
}

\author{
Mohammed Adamu1*, Lasisi Ejibunu Umoru², Oladeji Oluremi Ige ${ }^{2}$ \\ ${ }^{1}$ Department of Metallurgical Engineering, Kogi State Polytechnic, Lokoja, Nigeria \\ ${ }^{2}$ Department of Materials Science and Engineering, Obafemi Awolowo University, Ile-Ife, Nigeria \\ Email: ${ }^{*}$ mohammed2652@yahoo.ca
}

Received 29 January 2014; revised 5 March 2014; accepted 14 March 2014

Copyright (C) 2014 by authors and Scientific Research Publishing Inc.

This work is licensed under the Creative Commons Attribution International License (CC BY). http://creativecommons.org/licenses/by/4.0/

(c) (i) Open Access

\section{Abstract}

Inhibitors are regularly used as one of the principal prevention and control techniques in reinforcement corrosion. Hence this study investigates the effect of calcium nitrate and sodium nitrite inhibitors on the rebar corrosion of medium carbon steel in seawater and cassava fluid with a view to determining inhibitive potentials of the different inhibitors in the two media. Gravimetric and voltametric techniques were employed in this study and a total of forty-five corrosion coupons of different dimensions were produced. Forty coupons were used for gravimetric analysis and the remaining five for corrosion potentials measurements. Eight of the samples were used as control; while other eight samples each were admixed with calcium nitrate and sodium nitrite in concrete cubes. It was later immersed in seawater and cassava fluid for a total duration of 32 days and the measurements were taken at the interval of 4 days in order to determine the corrosion rates in mils per year (mmpy). Two controls and admixed samples each were later immersed in seawater and cassava fluid, respectively, for durations of $\mathbf{3 2}$ days to determine the corrosion potentials using a voltmeter and a Copper-Copper Sulphate Electrode $\left(\mathrm{Cu} / \mathrm{CuSO}_{4}\right)$. The $\mathrm{pH}$ of each medium was measured throughout the period of exposure. The results obtained expressed that all the samples except the control samples, displayed some degree of inhibition. The inhibition levels for the admixed samples in seawater were higher compared with those in cassava fluid. Inhibition efficiencies for various inhibitors followed different trends in different environment. The inhibition efficiencies for calcium nitrate in cassava fluid and seawater were $26.81 \%$ and $64.85 \%$ respectively. The study concluded that inorganic inhibitors were effective in inhibiting corrosion in cyanide and chloride contaminated concrete cubes.

\footnotetext{
${ }^{*}$ Corresponding author.
}

How to cite this paper: Adamu, M., et al. (2014) Effect of Calcium Nitrate and Sodium Nitrite on the Rebar Corrosion of Medium Carbon Steel in Seawater and Cassava Fluid. Journal of Minerals and Materials Characterization and Engineering, 2, 223-229. http://dx.doi.org/10.4236/jmmce.2014.23027 
Keywords

Inhibitor, Rebar Corrosion, Steel, Seawater, Cassava Fluid

\section{Introduction}

Corrosion is recognized as the number one life limiting plant degradation mechanism. It can attack insidiously yet the cumulative damage it inflicts and the cost of repair can be substantial and are well known but badly understood by those whose work involves the design, manufacture and maintenance of process equipment. This issue has resulted in the increasing interest in research into the environment/metal interface reactions and the means of reducing the damaging effects of corrosion on metals and alloys. Corrosion is an electrochemical process involving the oxidation of a metal and the corresponding reduction reactions [1]. Reinforcing bars corrosion embedded in concrete is the most common cause of deterioration of concrete structures in aggressive environments. Corrosion of steels reinforcement results in cracking and eventual spalling of concrete. In general, good quality concrete provides excellent protection for steel reinforcement. Due to the high alkalinity of concrete pore fluid, steel in concrete initially and, in most cases, for sustained long periods of time, remains in a passive state. Initiation of corrosion occurs either due to a reduction in alkalinity arising from carbonation or the breakdown of the passive layer by the attack of chloride ions. Chemical inhibitors can be effective in this type of application. Inhibitors are effective as a result of their controlling influence on the cathode- or anode-areas of reactions [2]. It is well established that inhibitors function in one or more ways to control corrosion: by adsorption of a thin film onto the surface of a corroding material, by inducing the formation of a thick corrosion product, or by changing the characteristics of the environment resulting in reduced aggressiveness [3]. Corrosion of reinforcing steel in concrete is brought about mainly by two factors. Firstly, it is due to the ingress of atmospheric carbon dioxide to the steel-concrete interface, and secondly, and more importantly, due to the diffusion of the chloride ions. The chloride ions were reported to be contributed by either the mix constituents or those entering the concrete from the external environment. The concomitant presence of sulphate salts with the chloride ions is known to aggravate the corrosive attack on reinforcing steel [4]. The focus of this research is to investigate the inhibitive potential of calcium nitrate and sodium nitrite on the rebar corrosion of medium carbon steel in seawater and cassava fluid. The scope of this work is to use these inhibitors in very small quantity which are within the range provided by the regulatory bodies and to use them in safe environments. The maximum concentrations of the inhibitors are less than $100 \mathrm{ppm}$ as advocated by OSHA. The environments obtainable in concrete industry have adequate ventilation and aeration which make them safe coupled with the expected high inhibition efficiency. Hence this study investigates the effect of calcium nitrate and sodium nitrite on corrosion associated with concrete industry.

\section{Experimental Details}

\subsection{Materials}

Medium carbon steel with a percent nominal composition of $0.347 \mathrm{C}, 0.214 \mathrm{Si}, 0.590 \mathrm{Mn}, 0.037 \mathrm{P}, 0.043 \mathrm{~S}$, 0.0052Co, $0.0083 \mathrm{Mo}, 0.119 \mathrm{Ni}$ and $0.229 \mathrm{Cu}$, the balance being Fe was used for this research. The chemical composition of the carbon steel was determined at Grand Foundry, Lagos. Crushed limestone with maximum size of $6.25 \mathrm{~mm}$ from Zerock quarry, Lokoja was used as coarse aggregate. Sand dunes from Obafemi Awolowo University, Ile-Ife with 2.64 specific gravity and $0.57 \%$ average absorption ratio was used as fine aggregate. Dangote portland cement was used in all the concrete mix. Seawater from bar-beach, Lagos and Cassava fluid freshly obtained from grated and squeezed cassava tubers at the Obafemi Awolowo University farm settlement, Ile-Ife served as the research environments. A pH meter (model pH2603) and an impedance voltmeter (model DT9205A) were used to determine the $\mathrm{pH}$ of the environments and the corrosion potentials. The two inorganic inhibitors (calcium nitrate and sodium nitrite) were commercially obtained for this research and the volume was kept constant at $45 \mathrm{ml}$.

\subsection{Preparation of Concrete-Cubes}

Concrete-cubes, $90 \times 50 \times 120 \mathrm{~mm}$ and $50 \times 15 \times 45 \mathrm{~mm}$ reinforced with $8 \mathrm{~mm}$ diameter medium carbon steel 
embedded at the centre were used for the corrosion studies. They had an effective cover of $50 \mathrm{~mm}$ and $15 \mathrm{~mm}$ at the bottom, respectively. A total of 45 concrete-cubes of different dimensions were cast to assess the effectiveness of inhibitors in retarding reinforcement corrosion. The mix ingredients in this case: portland cement (4.2 $\mathrm{kg})$, aggregate $(8.4 \mathrm{~kg}$ sand, $12.6 \mathrm{~kg}$ piedmont gravel), water $(1.97 \mathrm{~kg})$, and salt $(0.30 \mathrm{~kg})$. The concrete composition ratio (1:2:3 for cement:sand:gravel) was adopted [5]. Concrete constituents were mixed in a mixing pan for approximately 3 - 5 minutes until a uniform mixture was achieved. The moulds were filled with concrete in approximately three equal layers and vibrated for consolidation using physical effort. The inhibitors were added to the mixes by dissolving them in the mixing water. The concrete-cubes were performed on a single day for each of two batches of eight in a given set. Therefore, all concrete-cubes containing a given inhibitor treatment are the same age and subsequently tested at the same time. After casting, the specimens were covered with wet burlap for 12 hours. Thereafter, they were cured by covering them with wet burlap and plastic sheets for one week. The burlaps were wetted twice daily. Following the curing period, the specimens were exposed to different exposure conditions.

\subsection{Electrode Potentials Measurements}

Reinforcement corrosion was monitored by measuring the corrosion potentials using a Copper/Copper Sulphate electrode and a high impedance voltmeter (model DT9205A). These measurements provide qualitative information on the state of passivity of reinforcing steel [6].

\subsection{Gravimetric Measurements}

The rebar corrosion-cubes were immersed in seawater and cassava fluid, respectively, for an interval of 4 days each. After 4 days, a corrosion-cube was removed, the concrete-cube opened, the rebar sample cleaned thoroughly then weighed using a weighing balance. Weight loss measurements were taken at intervals of 96 hours for 32 days period of exposure using a chemical weighing balance (model FA2104A).

The corrosion rate of each sample was determined and calculated using the relation:

$$
R=\frac{534 W}{D A T}
$$

where $R$ is corrosion rate (mpy); $W$ is weight loss of samples (mg); $A$ is area of samples $\left(\mathrm{in}^{2}\right) ; T$ is exposure time (hr) and $D$ is density of medium carbon steel $\left(\mathrm{g} / \mathrm{cm}^{3}\right)$ [7].

The inhibitor efficiency $(P)$ in seawater and cassava fluid was determined from the relationship:

$$
P=100 \frac{\left(W_{1}-W_{2}\right)}{W_{1}}
$$

where $P$ is the Inhibition Efficiency (\%), $W_{1}, W_{2}$ are the corrosion rates in the absence and presence of the inhibitors, respectively.

\section{Results and Discussion}

\subsection{Corrosion Rate Measurements}

\subsubsection{Uninhibited Samples}

Corrosion rates for uninhibited samples in seawater and cassava fluid environments is presented in Figure 1. It was observed from the graphs that samples immersed in cassava fluid exhibited severe corrosion rates compared with samples in seawater. This could be as a result of the presence of cyanide ion $\left(\mathrm{CN}^{-}\right)$in cassava fluid which is more aggressive than chloride ion $\left(\mathrm{Cl}^{-}\right)$in seawater. The presence of carbohydrates and fats in cassava extract [8] are contributing factors for the corrosion of these metals. These constituents are sources of oxygen which may increase the oxidation process in the medium thus promoting corrosion of the materials.

When steel is immersed in cassava solution, corrosion commences with iron as the anode experiencing dissolution according to the reaction:

$$
\mathrm{Fe}=\mathrm{Fe}^{2+}+2 \mathrm{e}^{-}
$$

At the cathode, ionization of HCN occurs as follows [9]: 


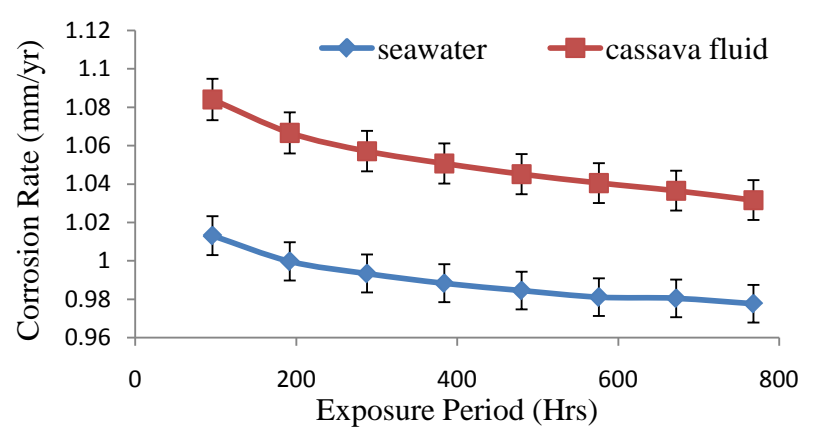

Figure 1. The corrosion rate of the uninhibited samples in seawater and cassava fluid environments.

$$
\mathrm{HCN}=\mathrm{CN}^{-}+\mathrm{H}^{+}
$$

The overall reaction according to the anode and the cathode reactions can be given as:

$$
\mathrm{Fe}^{2+}+2 \mathrm{CN}^{-}+2 \mathrm{H}^{+}=\mathrm{Fe}(\mathrm{CN})_{2}+\mathrm{H}_{2}
$$

Corrosion in seawater must have been as a result of intrusion of the inherently aggressive chloride ions $\left(\mathrm{Cl}^{-}\right)$, which are capable of destroying the passivating film around the steel reinforcement. A value of $0.5 \mathrm{~kg}$ of chloride per cubic metre of concrete has been accepted as the threshold to start serious corrosion [10]. Seawater contains chloride ions which are reduced to form hydrgen chloride and chloride ion. The decrease in $\mathrm{pH}$ of the concrete environment was as a result of the release of the hydrochloric acid $(\mathrm{HCl})$ as given in the equations below:

Local acidification of electrolyte by the reactions:

$$
\begin{gathered}
2 \mathrm{Fe}+2 \mathrm{Cl}_{2}=2 \mathrm{FeCl}_{2} \text { (unstable) } \\
\mathrm{FeCl}_{2}+2 \mathrm{H}_{2} \mathrm{O}=\mathrm{Fe}(\mathrm{OH})_{2}+2 \mathrm{HCl}
\end{gathered}
$$

The $\mathrm{pH}$ variation of the concrete environment with time exposure can be traced to Equations (6) and (7) during which the acidity of the concrete increase. That is, the decreae in the $\mathrm{pH}$ of the concrete was associated with the release of the $\mathrm{HCl}$ above. With the immersion of the medium carbon steel in seawater, it is most probable that corrosion sets in with dissolution of iron at the anode (Equation (8)), dissociation of $\mathrm{HCl}$ (Equation (9)) and consumption of dissolved oxygen and the electrons produced at the anode according to Equation (10).

$$
\begin{gathered}
\mathrm{Fe}=\mathrm{Fe}^{2+}+2 \mathrm{e}^{-} \\
\mathrm{HCl}=\mathrm{Cl}^{-}+\mathrm{H}^{+} \\
\mathrm{O}_{2}+\mathrm{H}_{2} \mathrm{O}+4 \mathrm{e}^{-}=4 \mathrm{OH}^{-}
\end{gathered}
$$

However, as soon as all the chlorides have been consumed and the production of $\mathrm{HCl}$ is halted, the overall reaction is expected to change to those of Equations (11) and (12), respectively, leading to the release of ferrous hydroxide, $\mathrm{Fe}(\mathrm{OH})_{2}$ or in the presence of surplus oxygen, ferric hydroxide, $\mathrm{Fe}(\mathrm{OH})_{3}$ as the corrosion products.

$$
\begin{gathered}
\mathrm{Fe}^{2+}+2(\mathrm{OH})^{-}=\mathrm{Fe}(\mathrm{OH})_{2} \\
\mathrm{Fe}^{3+}+3(\mathrm{OH})=\mathrm{Fe}(\mathrm{OH})_{3}
\end{gathered}
$$

These products are probably responsible for the increase in alkalinity of the concrete medium resulting in subsequent increase in $\mathrm{pH}$. The increased $\mathrm{pH}$ reduces the attacks of the medium carbon steel by the concrete medium. This trend is supported by Pourbaix diagram for iron-water system where $\mathrm{Fe}(\mathrm{OH})_{2}$ and $\mathrm{Fe}(\mathrm{OH})_{3}$ are the product of corrosion in alkaline medium.

\subsubsection{Inhibited Conditions}

Figure 2 presented corrosion rates of the uninhibited and inhibited samples in (a) seawater and (b) cassava fluid. It was observed from the data collected that corrosion rates decreased on the inhibited samples unlike the unin- 


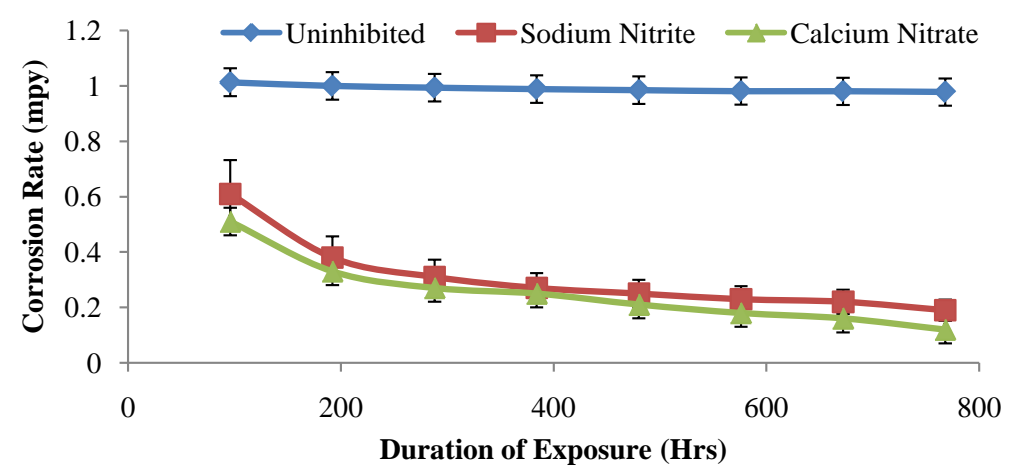

(a)

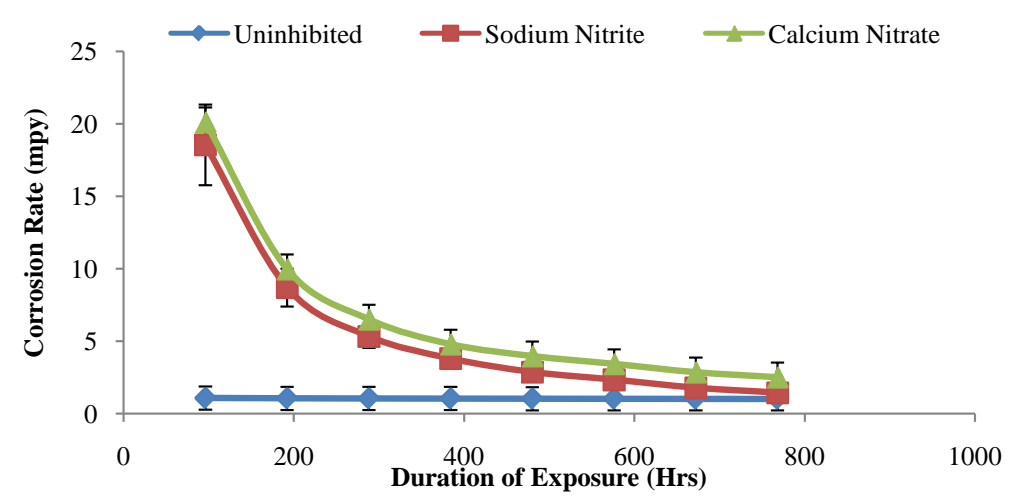

(b)

Figure 2. Corrosion rates of the uninhibited and inhibited samples in (a) seawater and (b) cassava fluid.

hibited. It shows that inorganic inhibitors possess inhibitive potentials in the two environments. Corrosion of metals in acidic medium has been attributed to the presence of water, dissolved oxygen, $\mathrm{O}_{2}$ in air and $\mathrm{H}^{+}$, which accelerate the corrosion process [11]. Figure 2(b) depicted corrosion rates of uninhibited samples in cassava fluid as almost non-existent while the uninhibited samples in Figure 2(a) expressed some rates of corrosion in seawater. Ordinarily, samples immersed in cassava fluid shows higher rates of corrosion compared with those in seawater environment. This assertion explained that cassava fluid have more aggressive ions than seawater but, Figure 2(b) indicated otherwise. This is mainly observed when a protecting film is formed on the samples surface which could hamper corrosion as observed in cassava fluid.

The specimen effectively predicted corrosion rates in both media with higher aggressiveness observed in cassava fluid compared with seawater environment. This is without recourse to specimens inhibition.

\subsection{Electrode Potential Techniques}

The effect of electrode potentials as a function of exposure time for rebar samples in seawater and cassava fluid for inhibited and uninhibited samples is shown in Figure 3. The tendency of any metal to react with an environment is indicated by the potential it develops in contact with the environment. In reinforced concrete structures, concrete acts, as an electrolyte and the reinforcement will develop a potential depending on the concrete environment, which may vary from place to place. The addition of inhibitors show similar trend that is, cassava fluid samples are more anodic than samples in seawater. The electrode potentials for inhibited samples moved in the cathodic direction implying that they are cathodic inhibitors. This implies that they will impede the reduction reactions. They have high over potential for hydrogen and they form precipitates at the cathode area [12].

\section{3. pH Measurement}

The $\mathrm{pH}$ data obtained is presented in Figure 4 and Figure 5 for the uninhibited and inhibited samples in seawater and cassava fluid, respectively. The $\mathrm{pH}$ data for seawater shifted towards neutral whereas those in cassava 


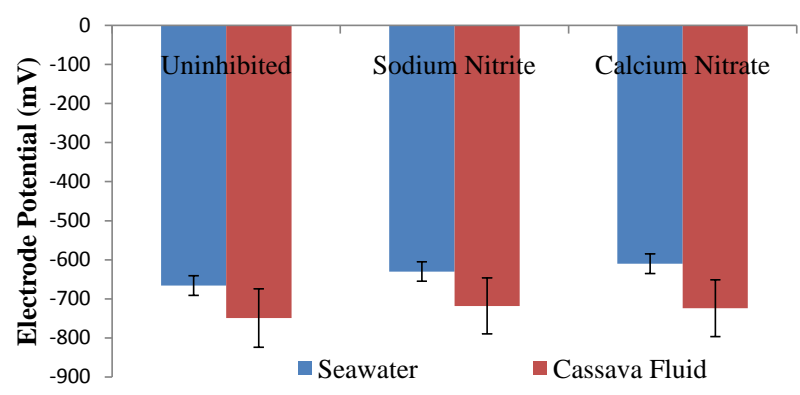

Figure 3. The effect of electrode potential on the uninhibited and inhibited samples in both seawater and cassava fluid environments.

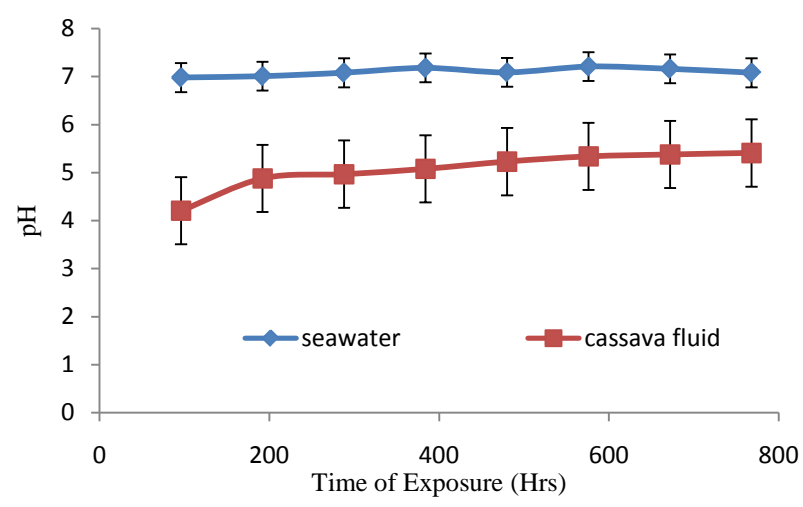

Figure 4. Effect of $\mathrm{pH}$ on uninhibited samples in both the seawater and cassava fluid environments.

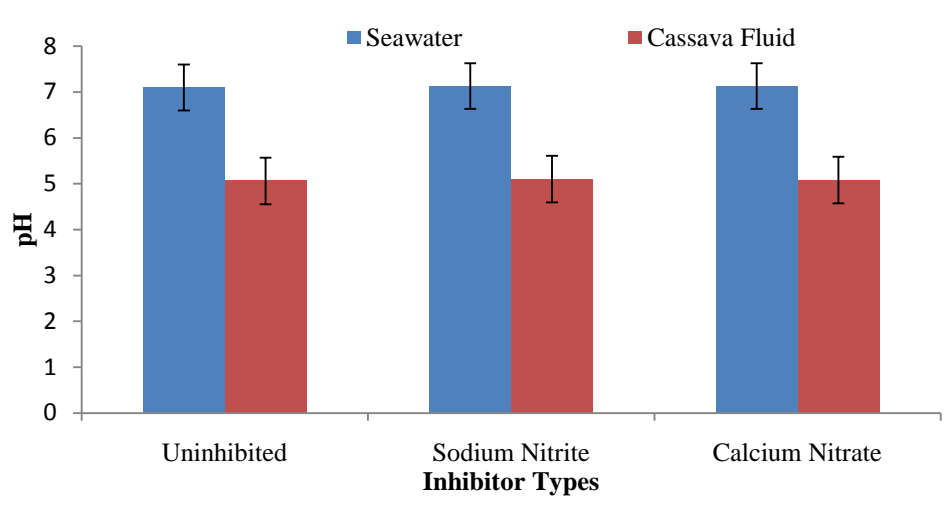

Figure 5. Effect of $\mathrm{pH}$ on the uninhibited sample and samples inhibited with different inhibitors.

fluid are acidic. This could account for the low degradation rates observed for steel immersed in seawater. The alkalinity of the media also increased with and without inhibitors, respectively. Therefore, it can be stated that the inhibitors are cathodic precipitators that precipitates insoluble compounds on the steel surface.

\subsection{Inhibition Efficiencies (\%)}

Figure 6 illustrated the inhibition efficiencies (\%) of the inorganic inhibitors in seawater and cassava fluid, respectively. Inhibition efficiency for inhibitors immersed in seawater displayed outright increment in the efficiency of both inhibitors mostly because the chloride ion $\left(\mathrm{Cl}^{-}\right)$in the seawater could not arrest the effect of the various inhibitors used whereas, observations from cassava fluid is different. Inhibition efficiency for the various inhibitors immersed in cassava fluid environment displayed early increase in the efficiency of the inhibitors 


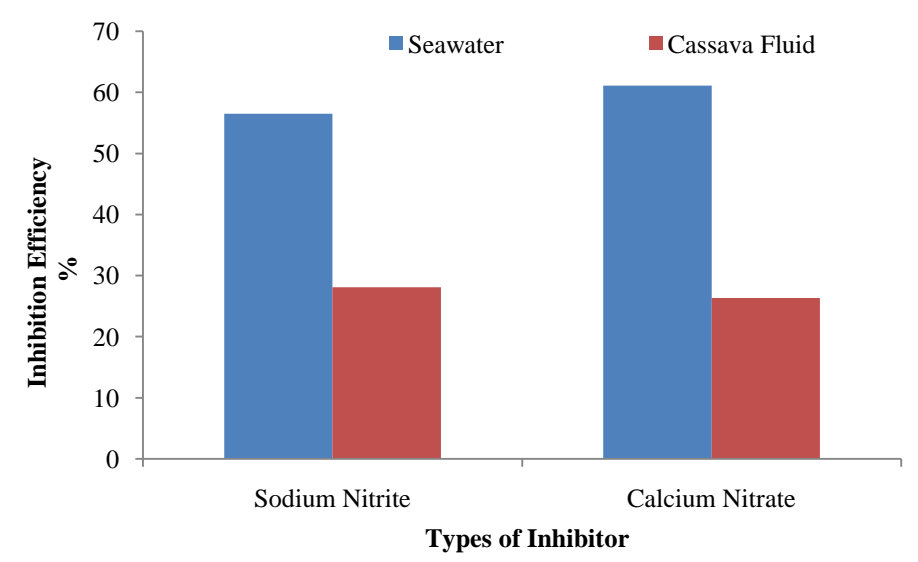

Figure 6. The inhibition efficiency in seawater and cassava fluid environments.

but maintains a uniform pattern thereafter. This can be attributed to the formation of a protecting film on the samples which consumed the effect of cyanide ion $\left(\mathrm{CN}^{-}\right)$in the cassava fluid.

\section{Conclusion}

The effect of calcium nitrate and sodium nitrite on the rebar corrosion of medium carbon steel in seawater and cassava fluid was investigated in relation to determining their inhibitive potentials. The rates of rebar corrosion in chloride and cyanide contaminated concrete specimen were also determined.

The results seem promising by showing a clear distinction in the corrosion rates of the inhibitive concrete specimen in that the inhibitive potentials on the specimen in seawater and cassava fluid differs; the rates of corrosion of specimen inhibited with sodium nitrite in seawater was higher than specimens inhibited with calcium nitrate. The reverse was noticed in cassava fluid environment with same inhibitive concentration.

The research therefore provided an avenue to see inorganic inhibitors as suitable in a rebar corrosion set-up.

\section{References}

[1] Charles, I.S. (1997) Improved Corrosion Inhibiting Pigments. Arabian Journal for Science and Engineering, $27,40-42$.

[2] Ailor, W.H. (1964) Handbook on Corrosion Testing and Evaluation. Wiley, Etobicoke, 1150-1165.

[3] Hackerrman, N. (1965) Fundamentals of Inhibitors. NACE Basic Corrosion Course, NACE, Houston.

[4] Al-Amoudi, O.S.B. and Maslehuddin, M. (1993) The Effect of Chloride and Sulphate Ions on Reinforcement Corrosion. Cement and Concrete Research, 23, 139-146. http://dx.doi.org/10.1016/0008-8846(93)90144-X

[5] Popovics, S. (1998) Strength and Related Properties of Concrete: A Quantitative Approach. John Wiley \& Sons, Inc., New York, 122.

[6] Maslehuddin, M. and Al-Amoudi, O.S.B. (1992) Corrosion of Reinforcing Steel in Concrete: Its Monitoring and Preventions. Symposium on Corrosion and Its Control. Pre-Print, King Saud University, Riyadh, 80-90.

[7] Fontana, M.G. and Greene, N.D. (1996) Corrosion Engineering. McGraw-Hill Book Co., New York, 28-116.

[8] Akindahunsi, A.A., Oboh, G. and Oshodi, A.A. (1999) Effect of Fermenting Cassava with Rhizopus Oryzae on the Chemical Composition of Its Flour and Garri. Rivista Italiana delle Sostanze Grasse, 7, 437-440.

[9] Olorunniwo, O.E., Umoru, L.E. and Bamigboye, O.R. (2008) Sodium Chromate and Diethylene Amine as Corrosion Inhibitors for Mild Steel in Cassava Fluid. Journal of Applied Science, 4, 878-882.

[10] West, R.E. and Hime, W.G. (1975) Chloride Profiles in Salty Concrete. Materials Performance, 5, 29-36.

[11] James, A.O. and Akaranta, O. (2009) The Inhibition of Corrosion of Zinc in 2.0 M Hydrochloric Acid Solution with Acetone Extract of Red Onion Skin. African Journal of Pure and Applied Chemistry, 3, 212-217.

[12] Hackerman, N. and Snavely, E.S. (1984) Corrosion Basics: An Introduction. NACE, Houston, 127-146. 